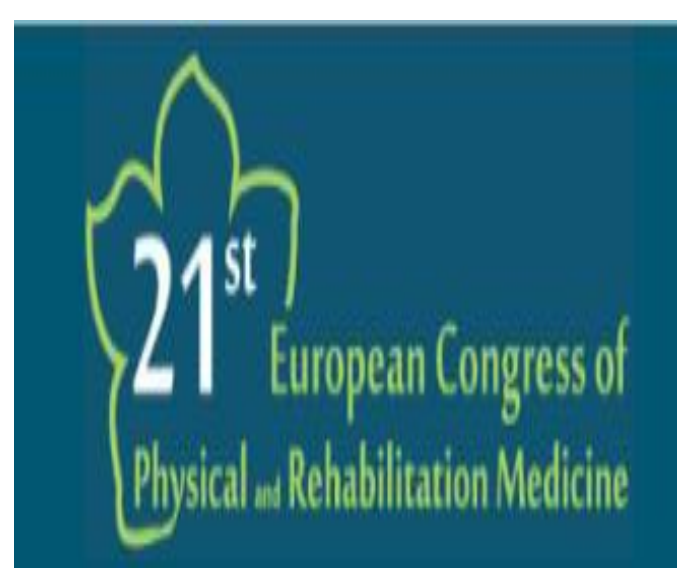

\title{
GENICULAR NERVE RADIOFREQUENCY ABLATION IN CHRONIC KNEE OSTEOARTHRITIS: LITERATURE REVISION
}

Miguel Joana ${ }^{1}$, Diana Mesquita ${ }^{1}$, Inês Natário ${ }^{1}$, João Carvalho ${ }^{1}$, José Carvalho ${ }^{1}$, Edgar Tamegão응 Sofia Amorim ${ }^{1}$, Gonçalo Borges ${ }^{1}$

${ }^{1}$ Physical Medicine and Rehabilitation, Hospital da Prelada, Serviço de Medicina Física e Reabilitação Porto, Portugal

\section{Introduction}

Osteoarthritis (OA) of the knee is one of the most common chronic diseases actuality and, with the increase in the average life expectancy, its prevalence and its incidence tend to increase. Several alternatives that aim at symptom control or with regenerative potential to reverse knee OA have been used, however, often failing to achieve satisfactory results.
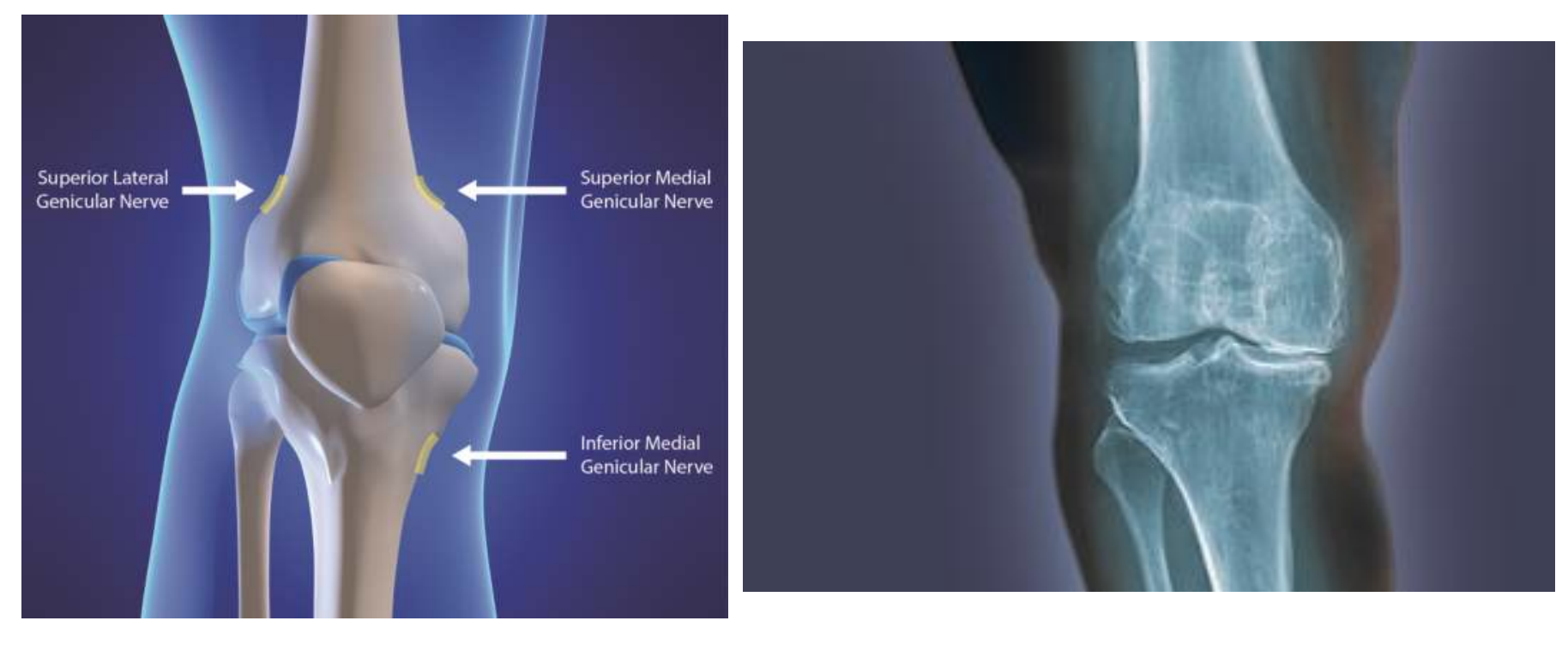

\section{Purpose}

Radiofrequency ablation of the genicular nerves is an interesting alternative to surgery for these patients suffering from chronic knee pain.

\section{Method}

Search in the electronic database Pubmed (limits: date of publication - last 10 years), using as keywords: "chronic knee osteoarthritis pain", "radiofrequency ablation" and "genicular nerves".

\section{Results}

In total, 20 articles were included in this review. Reviewing available information demonstrates that, in a large number of patients, a significant relief of pain occurs in assessments performed in the first three and six months after the intervention.

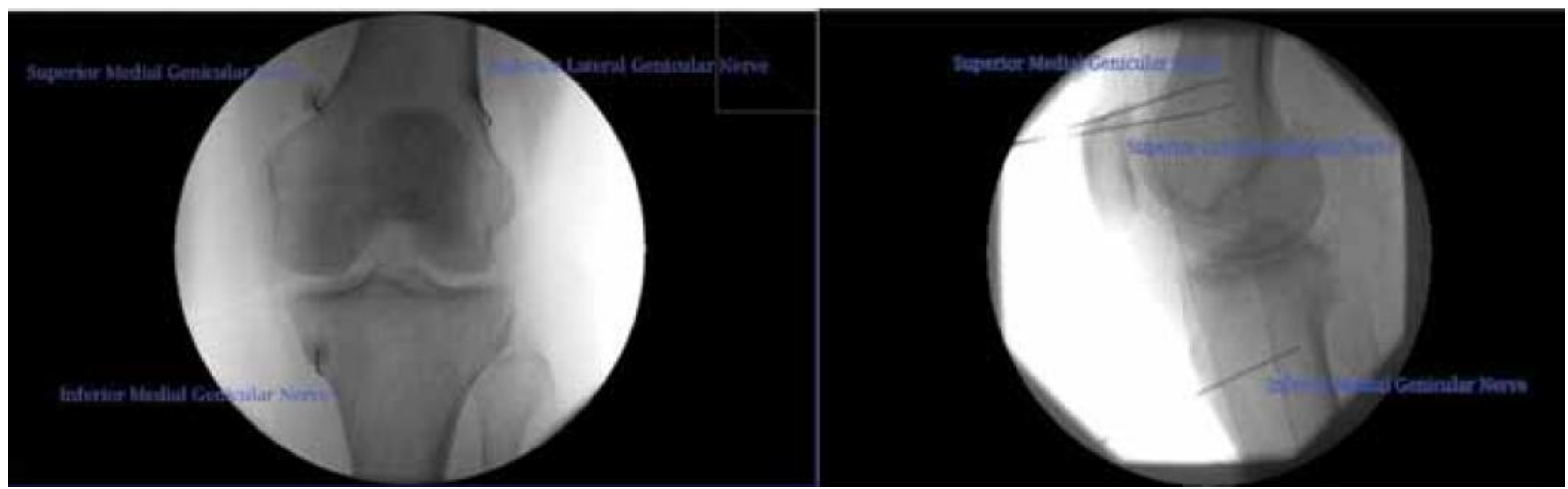

\section{Conclusion:}

With regard to pain control in knee OA, this therapeutic approach is undoubtedly a valid alternative, establishing itself as a bridge between the various minimally invasive treatments and knee arthroplasty. In the various studies, an interesting percentage of patients manifested positively with the results obtained. Further prospective studies in this area are needed to better understand the effects of radiofrequency ablation of geniculate nerves and evaluate their efficacy. 